\title{
Perencanaan Strategis Sistem Informasi pada Usaha Kecil dan Menengah
}

\author{
${ }^{1}$ Nizar Alam Hamdani ${ }^{2}$ Galih Abdul Fatah \\ ${ }^{12}$ Universitas Garut, Indonesia \\ Inizar_hamdani@uniga.ac.id \\ 2galihafm@uniga.ac.id
}

\begin{abstract}
Strategy Planning information systems are needed as part of a company's strategic planning. The planning of this information system strategy is structured as a strategy to win the competition so that the business performance of SMEs will increase. The purpose of this study is to formulate a strategy to describe the system objectives and technology architecture that will be implemented in SMEs. The method used in this study is to use the Strategic Information System Planning (SISP) version of John Ward and Joe Peppard (Ward \& Peppard). The results of the planning of information technology systems can be useful for SMEs in how to utilize information properly for their organizations. Based on these results SMEs must have the ability in the application of information technology so that it becomes an innovation to develop their business.
\end{abstract}

Keywords- Innovation, Strategic Information System Planning (SISP) , SME, Strategic Management.

\begin{abstract}
Abstrak: Strategi Perencanaan sistem informasi diperlukan sebagai bagian dari perencanaan strategis sebuah perusahaan. Perencaan strategi sitem informasi ini disusun sebagai strategi untuk memenangkan persaingan sehingga kinerja bisnis UKM akan meningkat. Tujuan dari penelitian ini adalah untuk merumuskan strategi untuk menggambarkan tujuan sistem dan arsitektur teknologi yang akan diimplementasikan di UKM. Metode yang digunakan dalam penelitian ini adalah menggunakan metode Strategic Planning Information System (SPIS) Versi John Ward dan Joe Peppard(Ward \& Peppard). Hasil dari perencanaan sistem teknologi informasi dapat bermanfaat bagi pelaku UKM untuk bagaimana mendayagunkan informasi secara baik bagi organisasinya. Berdasarkan hasil tersebut UKM harus memiliki kemampuan dalam penerapan teknologi informasi sehingga menjadi sebuah inovasi untuk mengembangkan bisnisnya.
\end{abstract}

Kata Kunci : Inovasi, Perencanaan Strategis Sistem Informasi, UKM, Manajemen Strategis.

\section{Pendahuluan}

UKM memiliki peranan strategis dalam membangun sebuah bangsa, hadirnya UKM dapat meningkatkan pertumbuhan ekonomi sebuah negara [1]. Senada dengan hal tersebut [2] menyebutkan bahwa UKM memiliki kotribusi besar dalam meningkatkan produk domestik bruto suatu bangsa. Beberapa penelitian menyebutkan bahawa Kinerja UKM ditentukan oleh teknologi diantaranya penelitian [3] dan [4]. Beberapa penelitian juga menjelaskan pentingnya peranan teknologi informasi pada UKM diantaranya [5] dan penelitian dari Oleh karena itu diperlukan perencanaan sistem informasi sebagai bagian dari implementasi teknologi yang dilakukan oleh UKM.

Penelitian yang dilakukan di negara-negara Amerika Latin membuktikan bahwa tingkat pertumbuhan kewirausahaan dapat meningkatkan indikator daya saing mereka yang kemungkinan menjadi faktor kunci dalam mencapai tahap pembangunan selanjutnya. Dengan kata lain, negara-negara yang memiliki faktor kewirausahaan positif akan memiliki daya saing yang positif [6].

Pada negara berkembang dinamika kewirausahaan dapat membantu untuk bertransisi dari "managed economies" menuju "entrepreneurial economies" [7]. Studi empiris lain yang dilakukan oleh pada berbagai negara dengan periode yang berbeda mengungkapkan bahwa ada berbagai jenis hubungan antara, seorang wirausaha ekonomi (factor driven), faktor pendorong efisiensi (efficiency driven), dan faktor pendorong inovasi (innovation driven) [8].

Usaha kecil dan Menengah (UKM) memegang peranan penting bagi perekonomian Indonesia, karena sektor ini dapat mengatasi permasalahan pemerataan dalam distribusi pendapatan antar wilayah. Selain itu UKM terbukti mampu bertahan dan terus berkembang di tengah krisis, karena pada umumnya sektor ini masih memanfaatkan sumberdaya lokal, baik itu untuk sumberdaya manusia, modal, bahan baku, hingga peralatan, artinya sebagian besar kebutuhan UKM tidak mengandalkan barang impor.

Jumlah UKM sampai dengan tahun 2015* (angka prediksi) sebanyak 3.615.650 unit usaha atau terdapat peningkatan sebanyak 2,6 \% dari tahun 2014 sebanyak 3.522.851 unit usaha. Perkembangan ukm Indonesia selama tahun 20102015 menunjukan terjadi peningkatan setiap tahunnya, walaupun demikian peningkatan setiap tahun masih di bawah $5 \%[9]$ 


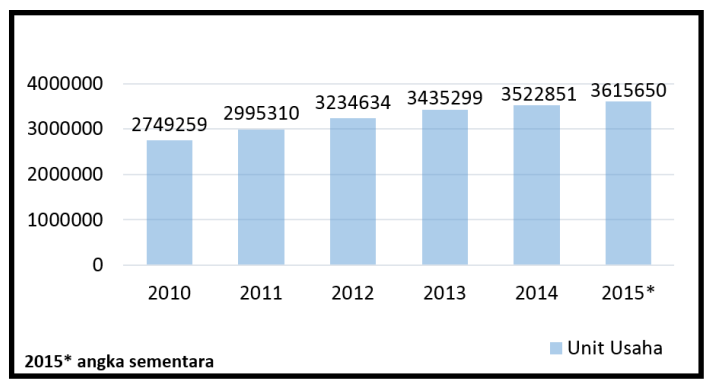

Gambar 1 : Perkembangan UKM di Indonesia Tahun 2010-2015

Penguasaan teknologi di UKM berbeda dari theory tentang penerapan teknologi yang banyak dijumpai di perusahaan besar. Secara teori pada umumnya para ahli mengemukakan peran Knowledge creation dan teknologi hanya diterapkan pada perusahaan besar tetapi secara empiris penerapan knowledge creation banyak dijumpai di SMEs [10]. Berdasarkan hal tersebut, dikemukakan juga bahwa teknologi mempunyai peran besar dalam pengembangan UKM[11].

Oleh karena iu penting untuk merencanakan strategi sistem informasi di UKM dengan memperhatikan aspek internal dan ekternal perusahaan sehingga menjadi strategi dalam menciptakan bisnis [12] dan [13]. Selanjutnya [14] menjelaskan bahwa penerapan strategi sistem informasi dapat meningkatkan daya saing UKM. Berdasarkan pemahaman theoritis dan empiris maka disusun perencanaan strategi sistem informasi untuk UKM Batik.

\section{KAJIAN LITERATUR}

Informasi memegang peranan penting sebagai alat untuk menintegrasikan sumber daya menjadi kemampuan daya saing pada perusahaan[15]. Beliau menjelaskan penelitian di bidang perencanaan strategi sistem informasi dalam beberapa dekade dalam tabel 1 berikut :

Tabel 1 : Penelitian strategi sistem informasi beberapa dekade

\begin{tabular}{|l|c|l|}
\hline \multicolumn{1}{|c|}{ Reference } & Term & Definition \\
\hline $\begin{array}{l}\text { Boynton and } \\
\text { Zmud (1987, p. } \\
59)\end{array}$ & $\begin{array}{l}\text { Information } \\
\text { technology } \\
\text { planning }\end{array}$ & $\begin{array}{l}\text { "Organizational activities directed toward (1) recognizing } \\
\text { organizational opportunities for using information } \\
\text { technology, (2) determining the resource requirements to } \\
\text { exploit these opportunities, and (3) developing strategies } \\
\text { and action plans for realizing these opportunities and for } \\
\text { meeting the resource needs." }\end{array}$ \\
\hline $\begin{array}{l}\text { Lederer and } \\
\text { Mendelow } \\
\text { (1988, (p. 445) }\end{array}$ & SISP & $\begin{array}{l}\text { "The process of deciding the objectives of organisational } \\
\text { computing and identifying potential computer applications } \\
\text { which the organisation should implement." }\end{array}$ \\
\hline $\begin{array}{l}\text { Lederer and } \\
\text { Sethi (1991, p. } \\
\text { 104) }\end{array}$ & SISP & $\begin{array}{l}\text { "The process by which [an] organization establishes a } \\
\text { long-range plan of computer-based applications in order to } \\
\text { achieve its goals." }\end{array}$ \\
\hline Earl (1993, p. 1) & SISP & $\begin{array}{l}\text { "Aligning investment in IS with business goals and } \\
\text { exploiting IT for competitive advantage." }\end{array}$ \\
\hline $\begin{array}{l}\text { Finnegan and } \\
\text { Fahy (1993, p. } \\
127)\end{array}$ & $\begin{array}{l}\text { Information } \\
\text { systems } \\
\text { planning }\end{array}$ & $\begin{array}{l}\text { "The broadly-based management activity that provides } \\
\text { direction, within an organizational setting for the } \\
\text { development and use of information systems." }\end{array}$ \\
\hline $\begin{array}{l}\text { Tan (1995, p. } \\
\text { 124) }\end{array}$ & $\begin{array}{c}\text { SISP } \\
\text { "A systematic methodology that provides a structural guide } \\
\text { should be adopted for the process which makes IT a } \\
\text { strategic weapon for firm." }\end{array}$ \\
\hline $\begin{array}{l}\text { Revenaugh and } \\
\text { Lu (1997, p. } \\
654)\end{array}$ & $\begin{array}{l}\text { Information } \\
\text { systems } \\
\text { planning }\end{array}$ & $\begin{array}{l}\text { "All planning activities that are directed toward identifying } \\
\text { opportunities for using IT to support the organization's } \\
\text { strategic business plans and to maintain an effective and } \\
\text { efficient IS function." }\end{array}$ \\
\hline $\begin{array}{l}\text { Fallshaw (2000, } \\
\text { p. 195) }\end{array}$ & $\begin{array}{l}\text { Information } \\
\text { technology } \\
\text { planning }\end{array}$ & $\begin{array}{l}\text { "Identification of the external factors that would affect and } \\
\text { influence strategic directions; consideration of II trends } \\
\text { and emerging technologies; a review and assessment of } \\
\text { the current IT environment; and finally identifying the } \\
\text { strategies and actions required to implement this vision." }\end{array}$ \\
\hline
\end{tabular}

Sejalan dengan hal tersebut pentingya perusahaan untuk menidentifiasi potensial sumber daya di bidang sistem infromasi merupakan hal penting yang harus dianalisis oleh perusahaan [16].

Konsep dari strategi sistem informasi diperkenalkan oleh Charles Wiseman pada tahun 1980 yang pada mulanya berfokus kepada tata kelola dan manajemen sistem informasi. Namun pada saaat ini strategi sistem informasi digunakan untu meningkatkan daya saing organisasi [17].

Perencanaan strategis Sistem InformasiI/Teknologi Informasi merupakan proses yag berkelanjutan dengan memperhatikan lingkungan ekternal perusahaan, lingkungan internal bahkan sekarang memperhatikan adanya perkembangan revolusi industri. Perbaruan itu bisa berupa revisi yang relatif kecil namun tidak tertutup kemungkinan dibutuhkan perubahan mendasar dan menyeluruh, bergantung pada keluasan cakupan proses strategis organisasi. Selain merupakan proses yang berkelanjutan, perencanaan strategis juga merupakan proses belajar [16].

Adapun tahapan tahapan dalam SISP menurut [18] adalah sebagai berikut : “(1) Strategic Business Planning: Prerequisite to systems planning: - It outlines an organization's overall direction, philosophy, and purpose. • It examines its current status in terms of its strengths, weakness, opportunities, and threats. - It sets long-term objectives. - It formulates short-term tactics to reach them, (2) Information Systems Assessment: Evaluation of the system to assess its status (current information systems resources) in terms of original or current expectations and how they are serving the organization, (3) Information Systems Vision: Ideal role that should be pursued for use of information systems resources. Information Systems Guidelines : (4) Set of statements that clarify use of organization's technical and information systems resources, (5) Strategic Initiatives: Three to five year long-term proposals that specify new initiatives for information systems organization"

Menurut [19] ada dua pihak yang memiliki peranan sentral dalam perencanaan strategi sistem informasi, yang pertama adalah yang disebut computer expert yang beraitan dengan perangkat keras, perangkat lunak, jaringan komunikasi dan sistem database. Sedangkan pihak yang kedua adalah perncang bisnis atau manager yang melakukan identifikasi, mengelola kemudian menjadikan sebagai asset bagi perusahaan.

\section{METODE PENELITIAN}

Metodologi yang digunakan dalam penelitain ini adalah mengacu kepada konsep perencanaan strategis yang dikemukakan Ward and Peppard. Pendekatan metodologi versi Ward and Peppard ini dimulai dari analisis kondisi bisnis dan investasi SI/TI yang sudah berjalan yang di nilai kurang efektif, lalu menganalisa kondisi bisnis eksternal 
sehingga dapat meningkatkan keunggulan kompetitif suatu organisasi. Analisis pemanfaatan SI/TI apakah sudah maksimal, lalu membandingkannya dengan kecenderungan kondisi SI/TI yang digunakan di luar. Karena, terkadang kurang bermanfaatnya SI/TI bagi organisasi disebabkan SI/TI lebih fokus ke teknologi, bukan berdasarkan kebutuhan bisnis [20].

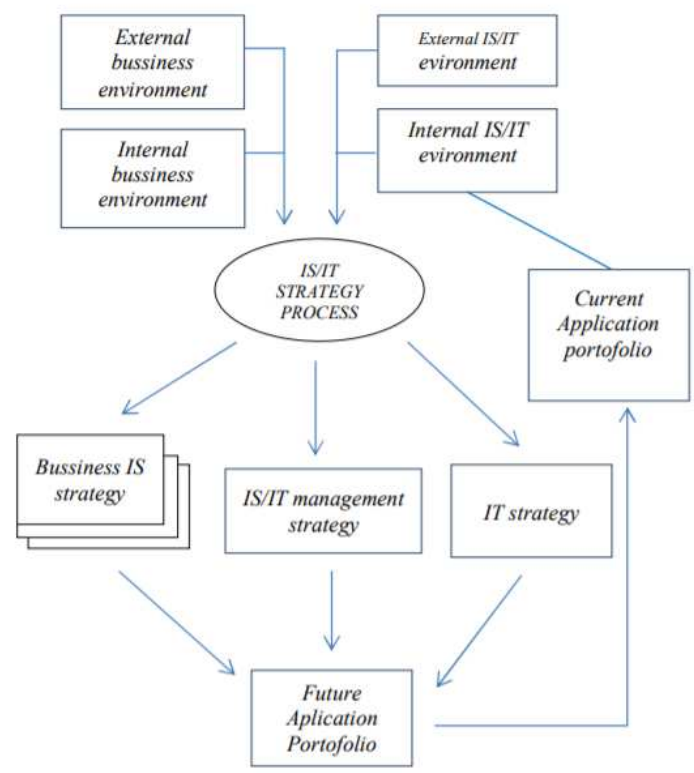

Gambar 2 Model Strategis SI/TI oleh Ward \& Peppard. [20]

Terdapat dua tahapan yang dilakukan untuk menyusun metode ward dan peppard untuk bisnis UKM. Tahapan yang pertama adalah tahapan input yaitu bagaimana melakukan analisis bisnis UKM Batik baik secara analisis internal maupun ekternal serta menganalisis sumber daya yang dimiliki SI/IT di bisnis UKM Batik serta analisis perubahan lingkungan SI/TI di bidang UKM Batik. Tahap kedua disebut tahap luaran yaitu adanya strategi SI dan TI serta strategi manajemen untuk SI/TI di bidang UKM Batik.

\section{IV.PEMBAHASAN}

UKM Batik di Jawa barat merupakan salah satu kegiatan usaha yang dilakukan oleh warga Jawa Barat berdasarkan warisan leluhur kebudayaan yang turun temurun yang menjadi daya tarik parawisata. Dalam melakukan analisis bisnis UKM Batik baik secara internal maupun eksternal, pelu adanya pendekatan menggunakan tool analisis SWOT. Berikut ini adalah hasil pemetaan analisis SWOT UKM Batik: Tabel 1. Matrik SWOT

\begin{tabular}{|c|c|c|}
\hline EFAS & $\begin{array}{ll}\text { Kelebihan (S) : } \\
\text { a. } & \text { Memiliki } \\
& \text { hubungan } \\
& \text { pemasok } \\
& \text { bahan baku } \\
& \text { sangat baik. } \\
\text { b. } & \text { Memiliki } \\
& \text { infrastruktur } \\
& \text { produksi } \\
& \text { yang } \\
& \text { menunjang } \\
\text { c. } & \text { Memiliki } \\
& \text { tim kerja } \\
& \text { yang solid } \\
& \text { dan inovatif } \\
\text { d. } & \text { Proses } \\
& \text { prokuksi } \\
& \text { batik tulis } \\
& \text { yang } \\
& \text { berkualitas } \\
\text { e. } & \text { Memiliki } \\
& \text { motif yang } \\
& \text { unik }\end{array}$ & 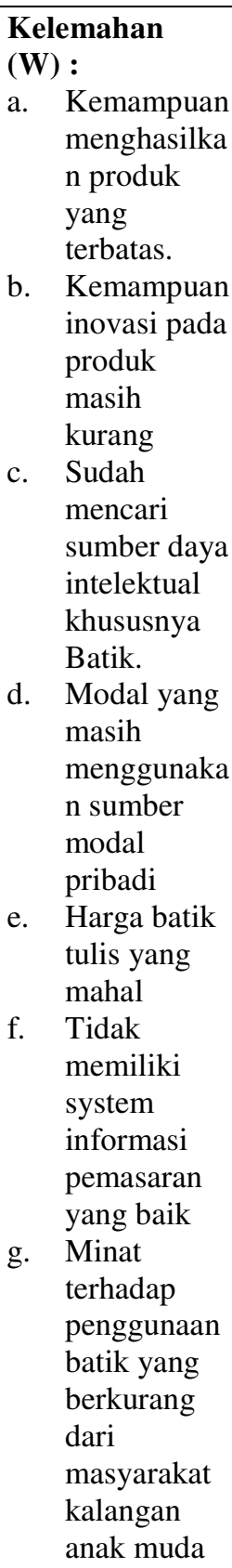 \\
\hline $\begin{array}{ll}\text { Peluang }(\mathbf{O}) \text { : } \\
\text { a. } & \text { Peningkatan } \\
& \text { Pengguna } \\
& \text { internet atau } \\
& \text { social media } \\
\text { b. } & \text { Kebijakan } \\
& \text { pemerintah } \\
& \text { Indonesia } \\
& \text { untuk } \\
& \text { mendukung }\end{array}$ & $\begin{array}{ll}\text { Strategi S-O : } \\
\begin{array}{ll} \\
\text { a. } & \text { Menerapkan } \\
& \text { sistem } \\
& \text { informasi } \\
& \text { manajemen } \\
& \text { supplier } \\
\text { b. } & \text { membuat } \\
& \text { program } \\
& \text { pelatihan } \\
& \text { yang lebih }\end{array}\end{array}$ & $\begin{array}{l}\text { Strategi W-O : } \\
\text { a. } \\
\text { Melakukan } \\
\text { pendidikan } \\
\text { dan } \\
\text { pelatihan } \\
\text { bagi UKM } \\
\text { Batik } \\
\text { terhadap } \\
\text { pengolahan } \\
\text { Batik yang } \\
\text { berkualitas }\end{array}$ \\
\hline
\end{tabular}




\begin{tabular}{|c|c|c|}
\hline $\begin{array}{ll} & \text { Batik Tulis } \\
& \text { Indonesia } \\
\text { c. } & \begin{array}{l}\text { Perubahan } \\
\text { Perilaku }\end{array} \\
\text { d. } & \text { Konsumen } \\
\text { Banyaknya } \\
\text { aktivitas } \\
\text { pemasaran } \\
\text { menggunaka } \\
\text { n intrenet } \\
\text { e. Pertumbuha } \\
\text { n ekonomi } \\
\text { di Jawa } \\
\text { barat yang } \\
\text { meningkat }\end{array}$ & 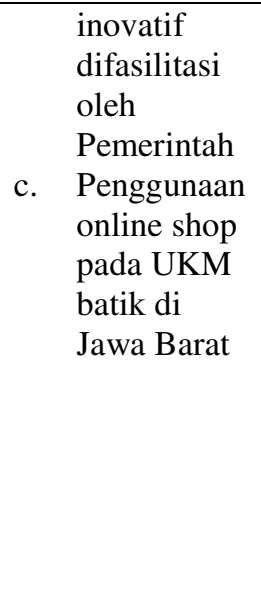 & $\begin{array}{ll}\text { b. } & \text { Pemerintah } \\
\text { memberikan } \\
\text { akses } \\
\text { pendanaan } \\
\text { melalui } \\
\text { perbankan } \\
\text { terhadap } \\
\text { UKM Batik }\end{array}$ \\
\hline 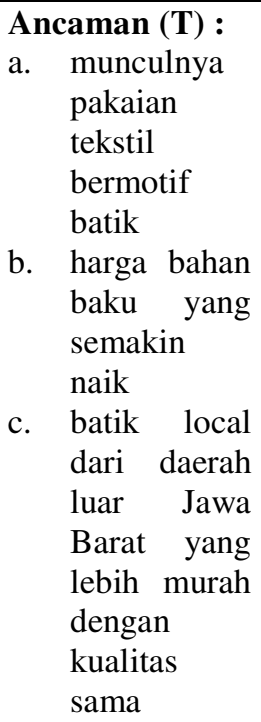 & 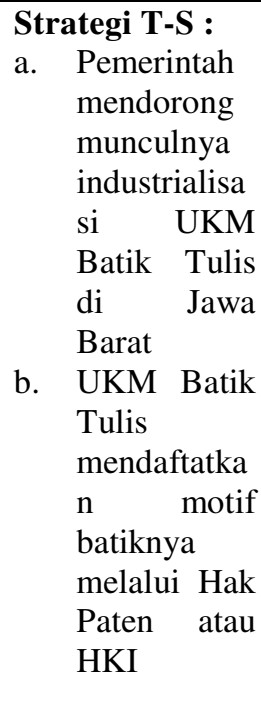 & $\begin{array}{ll}\text { Strategi W-T: } \\
\text { a. } & \text { Konsisten } \\
& \text { dalam } \\
& \text { menggunaka } \\
\mathrm{n} \text { aplikasi } & \\
\text { teknologi } \\
\text { informasi } \\
\text { yang ada } \\
\text { b. } \\
\text { Selalu } \\
\text { melakukan } \\
\text { evaluasi dan } \\
\text { monitoring }\end{array}$ \\
\hline
\end{tabular}

Berdasarkan hasil analisis SWOT dengan menggunakan pendekatan IFAS dan EFAS yang kemudian dipetakan ke dalam matriks grand strategy sehingga menghasilkan kesimpulan bahwa UKM Batik di Jawa Barat berada pada Kuadran I yang berkategori agresif. Hal tersebut mengindikasikan bahwa pertumbuhan UKM Batik tulis di Jawa Barat memiliki posisi yang menguntungkan bagi perusahaan karena saat ini terdapat beberapa kebijakan pemerintah yang mendorong agar masyarakat mengenalkan kembali penggunakan batik di masyarakat.

Strategi UKM Batik di Jawa Barat harus menerapkan dan mendukung kebijakan pertumbuhan yang agresif (Growth Oriented Strategy).

Kebijakan pertumbuhan yang agresif ini didesain untuk mencapai pertumbuhan, baik dalam penjualan, asset, profit atau kombinasi dari ketiganya. Hal ini dapat dicapai dengan cara menurunkan harga, mengembangkan produk baru, menambah kualitas produk dan meningkatkan akses ke pasar yang lebih luas.
Selain itu, UKM Batik di Jawa barat perlu melakukan analisis aplikasi portofolio. Analisis ini digunakan guna memetakan aplikasi atau teknologi informasi apa saja yang sudah digunakan oleh UKM dalam mendukung bisnisnya. Pemetaan ini terdiri dari empat kuadran yang memiliki kategori strategic, high potential, key operation dan support.

Analisis Aplikasi Portofolio adalah digunakan untuk memetakan aplikasi yang ada saat ini dan juga kebutuhan aplikasi dimasa akan datang dalam mendukung bisnis organisasi/perusahaan. Pemetaan aplikasi ini dengan empat kuadran (strategic, high potential, key operation, and support). Dalam analisis ini, UKM Batik dipetakan berdasarkan McFarlan Strategic Grid yang menggambarkan kontribusi SI/TI yang ada akan dinilai dengan empat kuadran.

Tabel 2

Current Application Portofolio UKM Batik

\begin{tabular}{|c|c|}
\hline Strategic & High Potential \\
\hline- & - \\
\hline- & $\begin{array}{l}\text { Pengguna laman } \\
\text { promosi website dari } \\
\text { pihak ke } 3\end{array}$ \\
\hline Key Operational & Support \\
\hline
\end{tabular}

Selain itu dalam menyusun sebuah perencanaan strategis system informasi pada UKM Batik di Jawa Barat perlu adanya penghubung antara strategi bisnis organisasi UKM Batik dengan strategi system informasi yang menitikberatkan pada proses perencanaan strategis SI pada area yang strategis, mementingkan usulan aplikasi SI dan mengevaluasi strategi system informasi. Hal tersebut dapat dianalisis menggunakan analisis Critical Success Factors (CSF) yang merupakan suatu ketentuan dari organisasi UKM Batik dan lingkungan sekitarnya yang berpengaruh pada keberhasilan atau kegagalan.

Dari hasil analisis terhadap kondisi lingkungan internal, eksternal dan aplikasi portofolio yang dilakukan tahapan sebelumnya yang menggambarkan aplikasi SI UKM Batik yang ada saat ini.

Maka perencanaan strategis bisnis dan sistem informasi UKM Batik di Jawa Barat untuk beberapa tahun yang akan datang dalam mempertahankan keunggulan dapat dilihat pada gambar table 3 berikut ini :

Tabel 3. Portofolio Aplikasi UKM Batik di masa yang akan datang

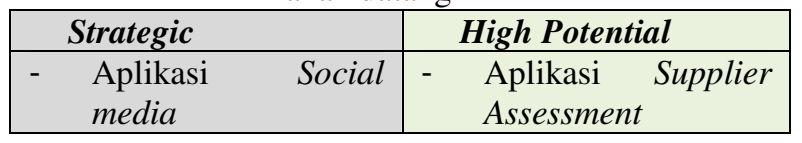




\begin{tabular}{|c|c|}
\hline $\begin{array}{ll}\text { - } & \text { Aplikasi Promosi } \\
\text { Edukatif } \\
\text { - } \quad \text { eCommerce } \\
\text { - eCatalogue } \\
\text { - website profil UKM } \\
\text { Batik }\end{array}$ & $\begin{array}{ll}\text { - } & \text { Aplikasi } \\
\text { kepegawaian }\end{array}$ \\
\hline $\begin{array}{ll}\text { - } & \text { Aplikasi Inventory } \\
& \text { Controll } \\
\text { - } & \text { Aplikasi Accounting } \\
\text { - } & \text { Aplikasi keuangan } \\
\text { dan Penggajian } \\
\text { - } \quad \text { Aplikasi Pendataan } \\
\text { dan penyimpanan } \\
\text { data pelanggan }\end{array}$ & $\begin{array}{ll}\text { - } & \text { Aplikasi Pendukung } \\
& \text { Keputusan } \\
\text { - } & \text { Aplikasi } \\
& \text { Penjaminan Mutu } \\
\text { - } & \text { Aplikasi Asset } \\
& \text { Manager } \\
\text { - Aplikasi } & \\
& \text { Penjadwalan } \\
\text { Produksi } & \text { Aplikasi } \\
\text { - } & \text { Manajemen Arsip }\end{array}$ \\
\hline Key Operational & Support \\
\hline
\end{tabular}

\section{KESIMPULAN}

Berdasarkan hasil beberapa analisis perencanaan strategis system informasi pada UKM Batik di Jawa Barat yang telah dilakukan, maka dapat diambil beberapa kesimpulan sebagai berikut :

1. Aplikasi yang berguna tetapi tidak menentukan kesuksesan yang digunakan oleh UKM Batik di Jawa barat adalah Aplikasi Pendukung Keputusan, Aplikasi Penjaminan Mutu, Aplikasi Asses Manager, Aplikasi Penjadwalan Produksi dan Aplikasi Manajemen Arsip.

2. Aplikasi yang mungkin akan menentukan keberhasilan dimasa datang pada UKM Batik di Jawa Barat adalah Aplikasi Supplier Assessment, Aplikasi kepegawaian.

3. Aplikasi yang saat ini sangat diperlukan dalam mencapai keberhasilan pada UKM Batik di Jawa Barat adalah aplikasi inventory control, aplikasi accounting, aplikasi keuangan dan penggajian, aplikasi pendataan dan penyimpanan data pelanggan

4. aplikasi penting untuk mendukung strategi di masa datang pada UKM Batik di Jawa Barat adalah Aplikasi Social Media, aplikasi promosi edukatif, ECommerce, E-Catalogue, Website UKM batik.

\section{DAFTAR PUSTAKA}

[1] G. Kadocsa, "Research of competitiveness factors of SME," Acta Polytech. Hungarica, vol. 3, no. 4, pp. 71-84, 2006.
[2] I. Hashi and B. a. Krasniqi, "Entrepreneurship and SME growth: evidence from advanced and laggard transition economies," Int. J. Entrep. Behav. Res., vol. 17, no. 5, pp. 456-487, 2011.

[3] N. A. Hamdani, G. Abdul, and F. Maulani, "The influence of E-WOM on purchase intentions in local culinary business sector," Int. J. Eng. Technol., vol. 7, pp. 246-250, 2018.

[4] N. A. Hamdani, "Building Knowledge Creation For Making Business Competition Atmosphere in SME of Batik," Manag. Sci. Lett., vol. 8, pp. 667-676, 2018.

[5] N. A. Hamdani and W. Susilawati, "Application of Information System Technology and Learning Organization to Product Innovation Capability and Its Impact On Business Performance of Leather Tanning Industry," Int. J. Eng. Technol., vol. 7, pp. 393-397, 2018.

[6] S. Singer, E. Amorós, and D. Moska, Global Entrepreneurship Monitor - 2014 Global Report. 2015.

[7] M. a Carree and a R. Thurik, Handbook of Entrepreneurship Research, vol. 5, no. 2004. 2010.

[8] P. Evangelista, E. Esposito, V. Lauro, and M. Raffa, "The Adoption of Knowledge Management Systems in Small Firms," Electron. J. Knowl. Manag. Vol., vol. 8, no. 1, pp. 33-42, 2010.

[9] BPS, "Statistik Indonesia 2016," 2016. [Online]. Available: www.bps.go.id. [Accessed: 10-Apr-2016].

[10] V. Rrustemi, "Organizational learning and knowledge creation processes in SMEs," J. Knowl. Manag. Econ. Inf. Technol., no. 6, pp. 1-21, 2011.

[11] J. Carr, "The Implementation of Technology-Based SME Management Development Programmes Diffusion of management learning technology from HE to SMEs," Educ. Technol. Soc., vol. 8, no. 3, pp. 206-215, 2005.

[12] Ö. Imre, "Adopting Information Systems in a Small Company: A Longitudinal Study," J. Appl. Econ. Bus. Res. JAEBR, vol. 6, no. 4, pp. 269-283, 2016.

[13] J. Nieto and Z. Fern, "The role of information technology in corporate strategy of small and medium enterprises," pp. 251-262, 2006.

[14] N. P. Singh, D. Molokov, S. Lechshak, and A. Kuspanov, "Information systems in small and medium enterprises in Republic of Kazakhstan," African J. Bus. Manag., vol. 6, no. 23, pp. 7042-7052, 2012.

[15] A. Amrollahi, "Three Decades of Research on Strategic Information System Plan Development," Commun. Assoc. Inf. Syst., vol. 34, no. 85, 2014.

[16] C. L. Wilkin and N. Cerpa, "Strategic Information Systems Planning: An Empirical Evaluation of Its Dimensions," Jpurnal Technol. Manag. Innovtion, 
vol. 7, no. 2, pp. 52-62, 2012.

[17] N. F. Alshubaily, "The Role of Strategic Information Systems ( SIS ) in Supporting and Achieving the Competitive Advantages ( CA ): An Empirical Study on Saudi Banking Sector," Int. J. Adv. Comput. Sci. Apllocations, vol. 8, no. 7, pp. 128-139, 2017.

[18] A. A. Altameem, A. I. Aldrees, and N. A. Alsaeed, "Strategic Information Systems Planning ( SISP )," in Proceedings of the World Congress on Engineering and Computer Science, 2014, vol. I, pp. 22-24.

[19] B. A. L. Lederer, "The Implementation of Strategic Information Systems Planning Methodologies," Strateg. Plan., vol. 2, no. September, pp. 445-461, 1988.

[20] W. R. King, "Strategic Planning for Management Information Systems MIS Strategic Planning --," MIS Q., vol. 1, no. March, pp. 27-37, 1978. 